\title{
La desaparición forzada en Colombia: Agendas pendientes de un problema no resuelto
}

\author{
The forced disappearance in Colombia: Pending agendas of an \\ unresolved problem
}

\begin{abstract}
RESUMEN
A partir de un proceso metodológico de revisión hermenéutica desde el paradigma crítico del Derecho, se plantea en este articulo de reflexión una aproximación al fenómeno de la desaparición forzada en Colombia, revisando el estado actual de la problemática con una mirada desde lo global y sus manifestaciones en lo local. Así mismo, se caracteriza la legislación construida en torno a la problemática y se precisan las agendas pendientes en un proceso de postconflicto.
\end{abstract}

\section{PALABRAS CLAVE}

Desaparición forzada, Derecho internacional, Jurisprudencia sobre desaparición forzada, Alter legalidad, Memoria de las víctimas.

\begin{abstract}
Based on a methodological process of hermeneutic revision from the critical paradigm of the law, this article discusses an approach to the phenomenon of forced disappearance in Colombia, reviewing the current state of the problem with a view from the global and its repercussion In the local, also, it is characterized the legislation built around the problematic and the pending agendas in a process of postconflict are specified.
\end{abstract}

\section{KEYWORDS}

Forced disappearance, Law international, Jurisprudence on forced disappearance, Alter legality, Memory of victims.

\section{WILMAN MAESTRE SÁNCHEZ}

Abogado egresado de la Universidad Simón Bolívar. Especialización en Derecho Penal de la Universidad Nacional. Candidato a Magíster en Derecho de la Universidad Sergio Arboleda Seccional Santa Marta. Actualmente trabaja como Fiscal especializado en la ciudad de Valledupar. wlmaestre@hotmail.com 
INTRODUCCIÓN: LA DESAPARICIÓN le los trabajadores del Salitre iniciaron una FORZOSA, EL DUELO CONGELADO EN EL TIEMPO

. que alguien me diga si han visto a $\mathrm{mi}$ hijo, es estudiante de pre-medicina; se llama Agustín y es un buen muchacho. A veces es terco cuando opina, lo han detenido, no sé qué fuerza, pantalón claro, camisa a rayas, pasó anteayer... a dónde van los desaparecidos. Busca en el agua y en los matorrales y por qué es que se desaparecen, por qué no todos somos igua les y cuándo vuelve el desaparecido, cada vez que lo trae el pensamiento, cómo se le habla al desaparecido, con la emoción apretando por dentro...

(Canción Los desaparecidos Rubén Blades

El poeta y diplomático Varujan Vosganian (2010) en su monumental obra El libro de los susurros, reconstruye la tragedia del proceso de eliminacionismo (Goldhagen, 2010) del pueblo armenio. Los convoyes de carros, la larga marcha al desierto de Deir-ez-Zo explicada desde la historia de vida de este intelectual armenio. Lo doloroso de lo narrado es que durante mucho tiempo, esta destrucción física y cultural pasó inadvertida por los meta-relatos de la historia oficial, de la historia que escriben los vencedores. $\mathrm{Na}$ die fue capaz de denunciar lo atroz de este sistemático proceso de desaparición de una nación entera.

América Latina no escapa a estos baches históricos, a estos orificios de la historia. En Chimarcha por sus reivindicaciones laborales, la gran huelga finalizó con la masacre de la escuela de Santa María de Iquique el día 21 de diciembre de 1907. El asesinato de más de 2.000 mil personas y la desaparición de su rastro físico así como de su memoria histórica van en concordancia con lo ocurrido al pueblo armenio.

En Colombia la masacre de las bananeras ocurrida el 5 y 6 de diciembre de 1928, evidencia este proceso de desaparición de las víctimas y de borrar su rastro histórico. Tal y como algunos niegan el holocausto nazi, en Colombia las cifras de las víctimas de las bananeras, se debaten entre el relato que los niega y el relato que los reclama. Solo las palabras provenientes del realismo mágico de García Márquez pueden encontrarle un sitio los asesinados y posteriormente desaparecidos de esta masacre: "... era un tren cargado de muertos que viajaba hacia el infinito".

Tal vez uno de los aspectos más documentados es el proceso de eliminación sistemática y cruel de los judíos, es el sistema represivo de noche y niebla iniciado por el régimen nazi y posteriormente estructurado bajo la denominación de la solución final en el holocausto, donde la sincronía para desarrollar el sistema de trenes de la muerte, campos de concentración y hornos crematorios, nunca falló.

Toda desaparición forzada comienza con la privación de libertad de la víctima, el delito en cuestión se propicia con el arresto, deten- ción o traslado contra la voluntad del agredido. Las Naciones Unidas precisan las dimensiones conceptuales que implica este acto tentatorio contra todos los derechos de un ser humano:

Es la privación de la libertad de una o varias personas mediante cualquier forma (aprehensión, detención o secuestro), seguida de su ocultamiento, o de la negativa a reconocer dicha privación de libertad o de dar cualquier información sobre la suerte o el paradero de esa persona, privándola así de los recursos y las garantías legales. (Naciones Unidas, 2012, p.15)

Las desapariciones forzadas se constituyen en una flagrante violación a los derechos humanos cuando esos actos son realizados por el Estado a través de sus funcionarios o personas o grupos que actúen con la autorización, apoyo, o en nombre del Estado. Es un crimen de lesa humanidad cuando, entre otras características, los hechos se cometen de manera sistemática (gran número de víctimas) o consecutiva (práctica frecuente) con el objetivo de sembrar terror.

En la actualidad los organismos internacionales especializados en el tema hablan de fenómeno de la Desaparición Forzada de Personas, en el marco mundial, sin distinción de ideologías políticas. Quiere deci que procede tanto en democracias como en dictaduras. Los cambios que se han dado en a concepción evolutiva del fenómeno han permitido que se tenga una noción más clara y certera acerca de los elementos y caracte- rísticas que deben tenerse en cuenta al momento de definirla.

Durante la época de las dictaduras y debido a la magnitud de la violencia de Estado que se alcanzó en América Latina, se dio a conocer un elevado número de víctimas y las dimensiones que el fenómeno de la desaparición forzada había alcanzado en el último cuarto de siglo; así mismo, se creó un ambiente doctrinal y jurisprudencial favorable a la tipificación internacional de este delito como "crimen de lesa humanidad". Como tal, la desaparición forzada no es prescriptible, ni amnistiable, ni permite el asilo y se obliga al Estado a procesar o extraditar a los victimarios (Lira Kornfeld, 2006).

Sin importar la guerza de las bases jurídicas, la utilización de la violencia como instrumento político ha sido una constante en la historia de la humanidad. De hecho, como plantea Apter (1997, p.207) "pocos cambios básicos en el contenido y alcance, lógica y prácticas de la libertad y la igualdad ocurren de modo pacífico, dentro de los marcos de la política institucional". Pero la violencia no solo está ligada a los cambios, sino también a la resistencia a los mismos, entre otras variables.

Esto significa que la violencia ha estado y está al servicio de actores y objetivos bien distintos. Sobre esta situación se observan las múltiples categorías en las que pueden clasificarse los diferentes modos de violencia política: genocidios, violencia étnica, guerra civil, terrorismo, asesinatos en masa, o la nueva categoria que se propone: eliminacionismo (Goldhagen, 2010). 
Pero aquí se produce una especie de para- que son 15 mil, el Comité Internacional de doja debido a que el uso de la violencia para la Cruz Roja precisa que son más de $100 \mathrm{mil}$ solventar los conflictos políticos está muy ex- y la Unidad de Víctimas contabiliza más de tendida en todo el mundo y ni la finalización 40 mil, aunque Medicina Legal estipule que de la Segunda Guerra, ni la caída del muro son 78.973. En esta investigación se asumen de Berlín, así como la declaratoria universal las estadísticas procesadas por el Centro $\mathrm{Na}$ de guerra al terrorismo han probado una fi- cional de Memoria Histórica (en adelante nalización o reducción de los niveles de vio- $\mathrm{CNMH}$ ): los desaparecidos por la violencia lencia; todo lo contrario, tenemos un mayor en Colombia suman un total de 60.632 pernúmero de conflictos políticos violentos en sonas. De las dimensiones trágicas de este todo el mundo, $y$ al mismo tiempo existe un problema y del marco nacional de este deamplio y frecuente rechazo a este tipo de ac- bate es donde surge la pregunta problema ciones en declaraciones formales y públicas.

A pesar de que Colombia se encuentra en una coyuntura especial, que anhela la paz soñada, es pertinente revisar una de las di-

ficultades más acuciantes de los problemas no resueltos en el acontecer sociopolítico del país: las desapariciones forzadas que han estado presentes en las confrontaciones no regulares de los diversos actores armados en la conflictiva historia colombiana.

Un conflicto que tiene sus raíces históricas y que ha dejado la triste marca del más. Más de ocho millones de víctimas, más de $260 \mathrm{mil}$ muertos, más de siete millones de desplazados internos y más de 11 mil víctimas por minas antipersonales. Pero lo que nos atañe, implica enfrentar la tragedia de la desaparición forzada, un crimen que no prescribe, pero que tampoco permite elaborar el duelo; es un crimen imperecedero en el tiempo, es un duelo congelado.

Existe un debate por la cifra exacta de los desaparecidos, la Fiscalía colombiana afirma que orienta este artículo de reflexión: ¿Cuáles son los avances jurídicos y su eficacia en problema de la desaparición for en Colombia?

La metodología se desarrolla en dos planos. El epistemológico que asume el paradigma de la hermenéutica jurídica, ya que gran parte del trabajo se inscribe en la comprensión de la esencia normativa, de ahí que se procesarán normas, leyes, y decretos en los contextos globales y nacionales. Para ello se validó la información a través de rejillas biliográficas, rejillas de análisis normativo rúbricas evaluativas que posibilitarán entender avances y retrocesos normativos.

El segundo plano, el conceptual, se inscribe en la tradición de los análisis críticos del Derecho, que revisa la opacidad de la Norma (Carcova, 2009) o el fetichismo jurídico (Lemaitre, 2007), que propende por comprender cómo la Norma tiene dificultades para materializarse en Estados anómicos, pero asi mismo, cómo el hecho de edificar normas puede crear movilizaciones sociales en torno al simbolismo jurídico, fenómeno analizado ampliamente por Mauricio García Villegas (2003) y al que Latorre denomina litigio estructural (Latorre, 2015).

El tema de la desaparición forzada es asumido desde múltiples miradas, dándose en su análisis y abordaje una visión interdisciplinaria. Desde la psicología se ha tratado de analizar la forma cómo los familiares de las víctimas asumen el proceso y las diversas estrategias resilientes, insistiendo en la forma de explorar el carácter de la resiliencia como herramienta de trascendencia del dolor (Giraldo Marín et al., 2008). Disiente en este sentido el trabajo longitudinal de Gabrie Gatti (2011), quien analiza los casos de desaparecidos en Uruguay y Argentina, especialmente la forma cómo los familiares que sobreviven al desaparecido niegan su ausencia o vivifican la misma a través de los silencios o las parodias propias del lenguaje cotidiano.

Los análisis normativos propugnan por una revisión de la evolución normativa y de sus ajustes entre los enfoques globales y los enfoques locales. En este sentido se pueden mencionar los análisis de Aguilar Cavallo (2009) sobre la normativa mexicana; de ah la importancia del análisis de las jerarquías, la naturaleza y fuentes de la jurisprudencia sobre la desaparición forzada en México. En ese mismo orden de ideas, el trabajo de Alflen da Silva (2010), quien analiza cómo un fallo judicial pone de relieve la ausencia en el Derecho Penal brasilero de la tipificación de delito de desaparición forzada.

El caso mexicano y sus abruptas desaparicio- nes son trabajadas en el detallado y crítico informe de Reveles (2015), quien precisa la realidad de una violencia que azota las estructuras legales del Estado mexicano:

En nuestra maltrecha democracia, la desaparición forzada de los 43 estudiantes de la Normal Rural "Isidro Burgos" en Iguala, Guerrero, en la noche del 26 al 27 de septiembre de 2014, visibilizó una violación cotidiana de derechos humanos. 43 dice mucho más que la mención de 130 mil ejecutados con violencia en México; es más contundente 43 que citar a millón y medio de desplazados; sacude más la conciencia 43 que la alusión a los no menos de 30 mil desaparecidos durante una absurda e inútil guerra al narcotráfico. Los 43 de Ayotzinapa fueron sacudida de conciencias para una energía social contenida durante años y que todavía busca los cauces que transformen esa indignación en acciones organizadas para un cambio radical y pacífico en México. Hay que sumar a esta barbarie a los otros 80 mil centroamericanos tragados por ese triángulo de las Bermudas de la violencia extrema en que se ha convertido la República Mexicana. (Reveles, 2015, p.9)

En orillas diferentes pero con realidades parecidas, el caso colombiano ha sido explorado de una forma innovadora por los trabajos cualitativos y cuantitativos que han logrado visibilizar los informes del Centro Nacional de Memoria Histórica. De manera holística e integrando el trabajo de campo con interrelaciones de variables estadísticas de variadas 
agencias del Estado y ONG, se ha realizado Ello implica una revisión sociohistórica de la una serie de investigaciones que precisan dinámica conflictiva del acontecer y estruc la magnitud del conflicto armado y que han turación de la Nación-Estado en Colombia, y sido publicados por diversos canales comu- en un segundo subtema, analizar los au nicativos.

Este esfuerzo se puede resumir en los siguientes trabajos: ¡Basta Ya! (Centro Nacional de Memoria Histórica, 2013) esfuerzo que cuantifica el daño al tejido social de la violencia, los cuatro volúmenes sobre desaparecidos. El primero de ellos (Centro Nacional de Memoria Histórica, 2014) explora las normas y dimensiones elaboradas para detener el fenómeno, el de la huella psicológica de las desapariciones en las familias (Centro Nacional de Memoria Histórica, 2014), el tomo dedicado a los recuerdos y rastros de los desaparecidos (Centro Nacional de Memoria Histórica, 2013) y finalmente el dedicado a realizar un balance de la acción del Estado (Centro Nacional de Memoria Histórica, 2014). Para destacar, el último informe titulado "Hay que encontrarlos" (Centro Nacional de Memoria Histórica, 2014) que cuantifica el tamaño de la tragedia de la desaparición forzosa.

A pesar de estos esfuerzos la tarea por cuantificar y explorar la magnitud de la trágica práctica del desaparecimiento forzoso sigue siendo necesaria e impostergable si queremos transitar el camino del postconflicto. En las siguientes líneas se propende por materializar los objetivos del trabajo que estuvieron orientados, en un primer ítem, comprender las dimensiones del problema de la desaparición forzosa en Colombia. manos condenó al Estado colombiano por la ejecución extrajudicial de este activista de derechos humanos, así mismo la Unesco declaró el archivo construido en libretas por la abnegada madre, dentro del patrimonio documental de América Latina y el Caribe.

Pero la lucha de la señora Lalinde solo ejemplifica la excepción entre los miles de casos que aún existen en Colombia, el esfuerzo de desenterrar La Escombrera, lugar de ejecuciones extrajudiciales en Medellín durante la cruenta guerra entre facciones paramilitares, guerrilla y Estado; simboliza los esfuerzos institucionales por hacerle frente a una de las manifestaciones de la guerra sin cuarte que por más de 50 años se libra en Colombia. Esta guerra contra la sociedad (Pecaut, 2001) tiene sus orígenes en los problemas históricos no resueltos en la construcción de Estado colombiano.

a pervivencia en el proceso de construcción de la Nación colombiana, de zonas grises, de lugares alter-legales donde el Estado no llega, hace que se pueda afirmar que Colombia es un Estado dual en los términos de Acemoglu y Robinson:

Colombia no es un caso de Estado fraca sado a punto de hundirse. Sin embargo, es un Estado sin centralización suficiente y con una autoridad lejos de ser completa sobre todo su territorio. Aunque el Estado pueda proporcionar seguridad y servicios públicos en grandes áreas urbanas como Bogotá y Barranquilla, existen partes significativas del país en las que proporciona pocos servicios públicos y prácticamente ninguna ley $y$ orden. En su lugar, existen grupos y personas alternativos... que controlan la política y los recursos. En algunas partes del país, las instituciones económicas funcionan bastante bien, $\mathrm{y}$ hay niveles elevados de capital humano y habilidad emprendedora; no obstante, en otras partes, las instituciones son muy extractivas, y ni siquiera proporcionan un mínimo nivel de autoridad estatal. ... La violencia y la falta de instituciones estatales centralizadas de este tipo inician una relación simbiótica con políticos que dirigen las partes funcionales de la sociedad. (pp.446-447)

Esta dualidad hace que nuestro país, durante más de 50 años, tenga oscilaciones constantes como un Estado en vías de fracasar o en estado de alerta, tal y como lo señaló el índice de Estados fracasados en el año 2005. Paradójicamente, en la actualidad, once años después, Colombia aparece como un Estado alertado con posibilidades de asumir el camino de un Estado fracasado.

Históricamente, el conflicto colombiano se describe como una confrontación interna, de origen ideológico, desarrollo irregular y duración prolongada, donde la población civil se ha convertido en la principal víctima, existen múltiples actores armados en heterarquias disruptivas y luchas de poder. Dicho conflicto lleva desangrando a Colombia desde mediados del siglo XX; se identifica por la generación de más de 6 millones de desplazados internos, con dramáticas consecuencias desde el punto de vista humanitario y 
desde la óptica de la protección de todos sus derechos.

Dichas violaciones han sido cometidas por miembros de las Fuerzas Armadas y de seguridad, así como por escuadrones de la muerte. El Alto Comisionado para los Derechos Humanos de las Naciones Unidas ha calificado tales violaciones como crímenes de lesa humanidad y crímenes de guerra (Comisión Internacional de Juristas, 2005, p.3). De la misma manera, es importante mencionar que la desaparición forzada era un método de disciplina y control social de comunidades enteras a quienes se les aplicaba esta modalidad para generar terror y así acabar con cualquier intención de denuncia u oposición a la estrategia paramilitar; por ende, serían reconocidos como la única autoridad imperante en determinadas zonas del territorio nacional.

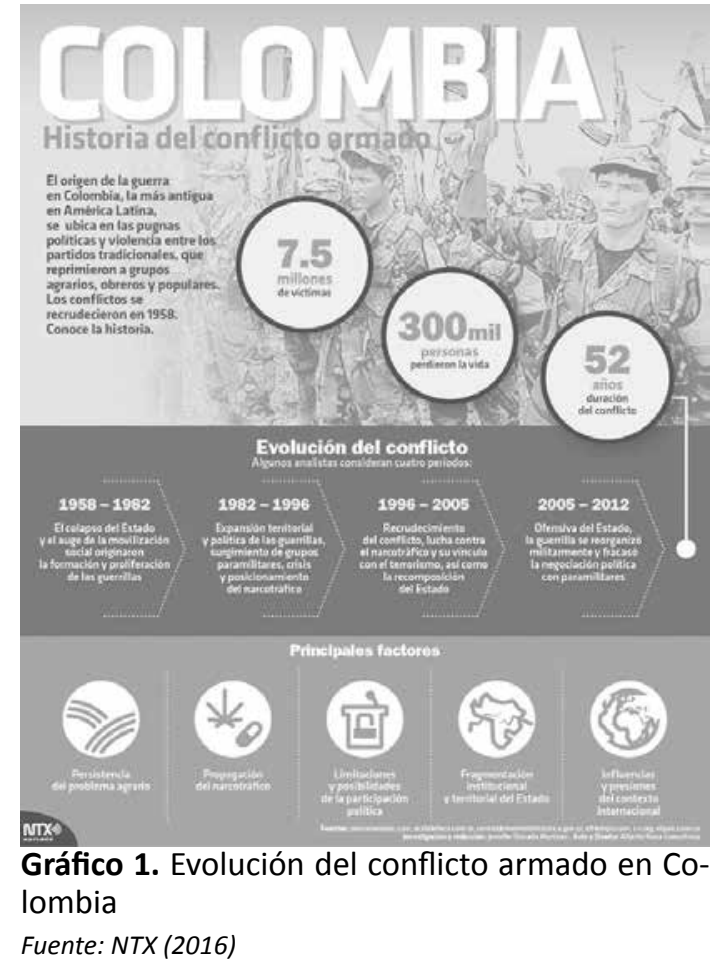

El conflicto en Colombia ha llegado a tener un dramatismo fatal para las víctimas de la guerra fratricida que nos ha afectado. Esto

se demuestra con las cifras comparativas en el nivel de personas en condición de desplazamiento a la fecha actual, donde Colombia ocupa el lamentable segundo lugar en desplazados internos:

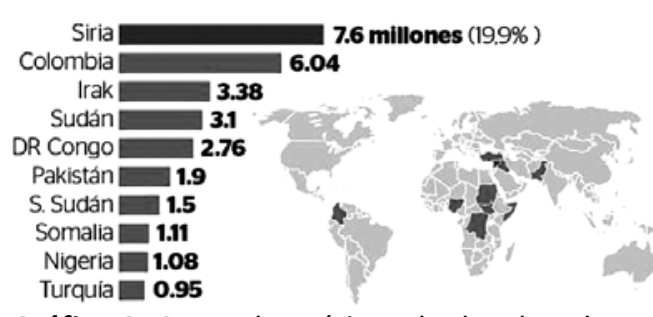

Gráfico 2. Casos dramáticos de desplazados

Fuente: Consejo Noruego de Refugiados (2016)

Pero fue con la expansión y consolidación de paramilitarismo organizado a gran escala en el territorio nacional que se dio un incremento de las desapariciones cometidas por esos grupos, que actuaban en muchos casos de manera coordinada con la Fuerza Pública, los cuales se beneficiaban de la omisión y tolerancia por parte del Estado y unas facciones de la población civil. El número de víctimas y uerra es abrumador, si se analizan los siguientes datos:

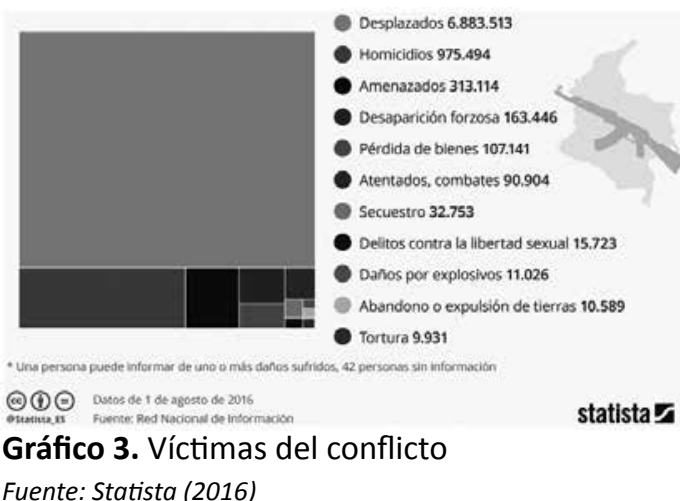

A continuación, unas estadísticas que confirman la sevicia de una guerra sin cuartel, datos tomados del informe iBasta Ya! del Grupo de Memoria Histórica de Colombia (2014):

1. Paramilitares: 8.902 asesinatos selectivos, 1166 masacres con 7.160 muertos, 371 casos de tortura y sevicia, más de 1.000 niños reclutados y despojo de 800 mil hectáreas de tierra.

2. Guerrilla: 24.482 secuestros, 3.900 asesinatos selectivos, 700 víctimas civiles en acciones bélicas, 854 ataques a poblaciones, 77 atentados terroristas, 343 masacres, más de 4.323 ataques a bienes de civiles, despojo de 800 mil hectáreas y casi 400 mil niños reclutados.

3. Fuerza Pública. 2.399 asesinatos selectivos, 158 masacres con 870 muertos, 182 ataques a bienes civiles.

De acuerdo con la investigación del CNMH (2014), el $99 \%$ de procesos abiertos en la Fiscalía por este delito (21.658 entre el 2005 y 2012) están apenas en etapa de indagación Tan solo hay 28 casos en juicio y 182 procesos terminaron tratados como 'querellables', es decir, como si fueran delitos menores. La mitad de las condenas se consiguieron por aceptación de cargos o negociaciones con los culpables. Lo que deja al descubierto es que el Estado no ha desarrollado mecanismos para fortalecer la investigación de estos casos, que inicialmente se trataban como secuestros, y que solo a partir del 2000 se consideraron como un delito independiente.

Por su parte, Amnistía Internacional en su informe 2014-2015, sostuvo que:
La población civil, especialmente los pueblos indígenas, las comunidades afrodescendientes y campesinas, los defensores $y$ defensoras de los derechos humanos, siguen siendo la más afectada por el conflicto armado. Según las cifras más recientes proporcionadas por la ONG Consultoría para los Derechos Humanos y el Desplazamiento (CODHES), casi 220.000 personas fueron objeto de desplazamiento forzado en 2013. Según la Organización Nacional Indígena de Colombia (ONIC), 10 indígenas fueron víctimas de homicidio por razones relacionadas con el conflicto, $y$ al menos 2.819 fueron víctimas de desplazamiento forzado durante los primeros nueve meses del año. En 2013 se tuvo noticia de 30 homicidios y 3.185 víctimas de desplazamiento forzado. Un informe publicado en 2013 por el Centro Nacional de Memoria Histórica, de carácter estatal, destacaba la magnitud de los abusos contra los derechos humanos. El informe concluía que, entre 1985 y 2012, murieron de forma violenta casi 220.000 personas, el $80 \%$ civiles. Al menos 25.000 personas fueron víctimas de desapariciones forzadas, cometidas mayoritariamente por paramilitares y fuerzas de seguridad. Alrededor de 27.000 personas fueron secuestradas entre 1970 y 2010, sobre todo por grupos guerrilleros, y más de 5 millones fueron objeto de desplazamientos forzados entre 1985 y 2012. Hasta noviembre, el Gobierno había registrado más de 7 millones de víctimas. (Amnistía Internacional, 20142015, p.131)

Una de las variables a estudiar es cómo el Es- 
tado colombiano es el mayor perpetrador en el tema de las desapariciones forzadas con las siguientes cifras, que se expondrán por temáticas coyunturales. Estas delimitaciones temporales sirven de referente sobre los discursos, con los cuales se trato de legitimar e accionar de los escuadrones de la muerte al servicio del Estado colombiano:

1. Contrainsurgencia. El caso clave en la coyuntura de 1970 a 1982 es el denominado Colectivo 82, donde narcotraficantes bajo el pretexto de la amenaza comunista contratan policías para desarrollar actividades de desaparición forzada.

2. Triunvirato de la muerte. Entre los años 1983 y 1993, las asociaciones ilícitas entre empresarios-militares-escuadrones de la muerte, generan una alta tasa de desapariciones, a pesar de ser eliminado el Estatuto de Seguridad y de disminuir la tortura como práctica y la detención ilegal.

3. Al filo del caos (1985-1990). La toma de Palacio de Justicia propició la desaparición de 11 personas, que hoy por hoy se ha podido constatar que salieron vivas después de la retoma por parte de los militares; en 1987 la masacre de 19 comerciantes en Puerto Boyacá instaura el régimen del terror de los escuadrones de la muerte; en 1988 la desaparición forzada de la activista Olga Esther Bernal, en Buenaventura, y el caso de desaparición orzada en Casamachín en medio de una operación militar en La Uribe, Meta.

4. Estigmatización con el discurso de la contrainsurgencia (1994-2002). Este proceso se caracteriza por la consolidación de paramilitarismo en Colombia como una opción legitimada en la narrativa de la autodefensa. Sus crueles resultados basados en la pedagogía del miedo terminan propiciando 25 personas desaparecidas en Barrancabermeja, 26 indígenas Embera Katíos en Murindó, Antioquia, así mismo, la desaparición de 4 hermanas de la familia Galárraga en La Dorada Putumayo.

La era de la seguridad democrática y los falsos positivos (2003-2012). El discurso de la seguridad democrática y la doctrina de terrorismo global se aúnan en una combinación peligrosa, donde la persecución a la oposición, el control geográfico de ciertos espacios territoriales y la búsqueda de zonas con recursos claves para la guerra generan una política de terrorismo de Estado que finaliza con los Falsos Positivos (Falsos Positivos en Soacha).

En Argentina, entre 1976 y 1983, desaparecieron 10.000 personas. En Chile, entre 1973 y 1990, desaparecieron 3.500. En Uruguay, entre 1973 y 1985, desaparecieron 300 personas. Según reportes oficiales en las dictaduras de Argentina, Chile y Paraguay, se dieron 10.464 desaparecidos, menos de mitad que las reconocidas hoy en Colombia. Dolorosamente los colombianos vivenciamos entre 1996 y 2005, que cada dos horas desapareciera una persona.

Según el registro nacional de desaparecidos 2011, se dieron 16.907 casos. El registro único de víctimas especifica que entre 1985
2012 se dieron 25007 víctimas de desapa- $\quad$ un lapso de 45 años desapareció el 51,4 \% rición forzada. De las cuales fueron perpetradas por un autor desconocido: 21.423 es decir, el 86 \% según el RUV. Los delitos de desaparición Confesados en Justicia y Paz a 2012 registran un total de 8.360 casos. A continuación una sintesis del último informe sobre desaparecidos producido por el Centro Nacional de Memoria Histórica (2016) que hace un análisis de 45 años sobre el fenómenos y llega a las siguientes conclusiones: 31.183 casos); no se conoce quién es el autor en el $48,6 \%$ (29.447). Se dividen los victimarios de la siguiente forma:

- Paramilitares: 1356

- Guerrilleros: 5849

- Grupos post-desmovilizados: (2598)

- Agentes del Estado: (2368)

- Grupos armados no identificados: (4686).

A continuación el promedio de personas desaparecidas:

Entre 1970 y 2015, desaparecieron 60.630 • 43,3 \% son campesinos personas. Lo que más se menciona: Palacio - 15,6 \% empleados y profesionales

de Justicia 1985, Masacre de Trujillo 1986- • 14,1 \% comerciantes y vendedores am1994, Desaparición Colectiva de comercian- bulantes

tes en 1989, Mapiripam en 1987, Desapari- • 10,8 \% combatientes (fuerza pública,

ción colectiva de Barrancabermeja en 19

Operación Orión y La Escombrera en 2012 os Falsos Positivos en 2008. guerrilleros y paras)

- $4 \%$ funcionarios públicos

- $2,2 \%$ estudiantes

- $10 \%$ otros

Hay víctimas de desaparición forzada en $\bullet 87,8 \%$ son hombres

1010 de los 1.115 municipios del país. Dos de • 12,2 \% son mujeres

cada tres desapariciones forzadas se concen- 58,6\% edades entre 18 y 55 años

tran en 130 municipios que registraron cada • 3075 plenamente identificados

no más de 100 desapariciones forzadas. Las 5 subregiones más afectadas por la crueldad de la práctica con más de tres mil desaparecidos son:

1. Ariari Guayabero: 3.087

2. Sierra Nevada de Santa Marta: 3.208

3. Urabá: 3421

4. Valle del Aburrá: 3.523

5. Magdalena Medio: 4.712

Responder a la pregunta de quiénes son las de ellas ubicadas en las fincas de narcotravíctimas es clave. Un total de 60.630 desa- ficantes, ganaderos y paramilitares, tirados a parecidos entre los años 1970 y 2015. En los ríos, o a animales salvajes como cocodri- 
los o incluso incinerados en hornos crematorios preparados con el fin de no dejar rastro de las víctimas (CNMH, 2016).

Después de una larga época de impunidad para los autores de la desaparición forzada en el año 2000, con la Ley 589, esta cruel e inhumana práctica, comenzó a ser reconocida como un delito y a su vez, a ser considerada y documentada por los organismos judiciales. Esas décadas de conflicto interno han evidenciado su participación, a través de diferentes actores, a iniciar, aumentar y mantener la desaparición forzada como una de las desgracias más sufridas en Colombia; siendo este el país con más desaparecidos en Latinoamérica.

Pero este delito no se detiene con la desaparición; queda el sufrimiento de familiares,

amigos y conocidos que viven día a día con la incertidumbre de no saber cuál ha sido el fin de dichas víctimas, por lo cual nacen las secuelas que los afectan psicológicamente, las cuales no se superan o no se curan fácilmente $y$ otras en las que ese ciclo llega a su fin solo cuando son reconocidos -en su mayoría- por pruebas de $A D N$ a sus seres queridos.

El rezago en la aplicación de la justicia para los victimarios se evidencia en el bajo núme-

ro de personas castigadas por dicha calamidad; además, el Estado es ineficiente al no tomar una posición firme para terminar con la búsqueda de miles de familias, algunas de las cuales llevan décadas esperando no- De acuerdo con la Declaración Universal de ticias de sus seres queridos. Veamos a conti- Derechos Humanos, la desaparición forzada

nuación cuales han sido los logros y las deu- es un crimen reprochable en contra de los das pendientes de un problema no resuelto en la jurisprudencia colombiana.

2. Caracterización de los avances jurídicos en torno a la desaparición forzosa en Colombia: respuestas desde la glocalidad

Uno de los presupuestos de la globalización es que tanto sus beneficios como problemáticas son producto de una dualidad e interaccion constante. Esta dicotomía interactiva es la que se denomina la glo-calidad (global y local, genera la palabra glo-cal). El mundo de lo juridico no escapan a esta poderosa megatendencia. Por eso podemos afirma que hay problemas globales que repercuten en lo local y también respuestas globales que se manifiestan en las localidades (Friedman 2012).

La problemática de la desaparición forzosa es asumida en los contextos globales ya que sus incidencias se manifiestan de forma similar en todos los órdenes estatales con problemáticas de monopolio de la violencia. En este orden de ideas existen varios instrumentos internacionales que velan por la protección de las personas contra la desaparición forzada; algunos tienen el carácter de tratados, otros son declaraciones, pero poseen entre sus objetivos, el velar y salvaguardar los derechos humanos de la población en los diferentes países del mundo. normativo y las fuertes tendencias globales derechos humanos, enunciado en su artículo 12 en donde se promulga que nadie será sometido a esta práctica. Esa promulgación sirve como base importante para que la comunidad internacional esté atenta y vigilante a cómo se está llevando a cabo el respeto de los derechos humanos, y más aún en un país como Colombia, que vive en constantes conflictos internos en los cuales se confronta un conjunto de actores armados en luchas territoriales.

Por otro lado, el Pacto Internacional de Derechos Civiles y Políticos (ICCPR) después que fue ratificado por Colombia el 29 de octubre de 1969, así como los demás instrumentos internacionales de derechos humanos, tienen categoría de normas constitucionales $y$ por consiguiente prevalecen en el orden interno. El Pacto, como su nombre lo indica, reconoce los derechos civiles y políticos de los individuos e igualmente establece los mecanismos para su protección y garantía. En su artículo 15 hace alusión a la desaparición forzada, párrafos que condenan dichas conductas.

gualmente, la Convención Internaciona para la Protección de las Personas contra las Desapariciones Forzadas es uno de los tratados de derechos humanos más fuertes que ha sido adoptado por las Naciones Unidas. Ella se crea debido a la presión ejercida por los familiares de las víctimas de desaparición forzada que buscaban que fueran reconocidas como un crimen contra la humanidad. objetivo de esta Convención es mejorar los instrumentos de la ley internacional para abordar el gran problema de las desapariciones en todas aquellas partes donde dichas violaciones ocurren o podrían ocurrir y de esta forma visibilizarlas en sus países y en el mundo.

Dicha Convención trata exclusivamente los temas de desaparición forzada; convirtiéndola en una institución importante, debido al trabajo que se ha desarrollado y además a los pronunciamientos, denuncias, medidas preventivas, cooperación internaciona, el reconocimiento a las víctimas, sus derechos, estudios que giran en torno al tema para lograr un amplio alcance, un gran impacto social, político y jurídico en los países que así lo requieran.

El artículo 7 del Estatuto de Roma, del 17 de julio de 1998, incluye el Delito de Desaparición Forzada, como un crimen de lesa humanidad, y hace una definición de lo que es la desaparición forzada y condena su acción independientemente del actor que lo haya perpetrado. Es imprescindible nombrar a la Corte Interamericana de Derechos Humanos, que ha condenado en varias ocasiones al Estado colombiano; se considera que sus sentencias no van acorde a la gravedad de las situaciones juzgadas. Las sentencias de la Corte se justifican a través de las reglas procesales internacionales de Derechos Humanos o la gravedad de los asuntos tratados por esta jurisdicción.

Colombia es el segundo país con el mayor número de fallos de la Corte Interamericana de Derechos Humanos de todo el hemisferio, 
solo por debajo de Perú. Hasta el año 2013 sea las instancias internacionales actúan habían sido 14 ocasiones en que la Corte como entes vigilantes de las personas ante Internacional de Derechos Humanos juzgó y condenó al Estado colombiano por haber vulnerado los derechos humanos en casos como: las Masacres de Ituango, Mapiripán y Santo Domingo, y la toma del Palacio de Justicia.

En esta última, el Estado fue condenado por décimoquinta vez por su responsabilidad en las 11 desapariciones del Palacio de Justicia los días 6 y 7 de noviembre de 1985. Estos fallos implicaron que el Estado indemnizará por una millonaria cantidad a las víctimas, asi como un acto de perdón, que incluye la realizacion de un documental. A su vez, que cos-

teara tratamientos psiquiátricos; así mismo se le ordenó al Estado hacer lo que esté a su alcance con el objetivo de lograr resultados judiciales a la mayor brevedad.

Como se ha visto, en la actualidad la catástrofe de la desaparición forzada está tipificada como delito a nivel mundial; lo cual le da más herramientas a las víctimas y además les permite tener acceso más allá de las fronteras de donde ocurren dichas vulneraciones, si se evidencia que en sus países no encuentran las garantías o la seguridad para que les sean salvaguardados sus derechos.

Esas instancias internacionales fueron creadas con el objetivo principal de velar y observar ante los Gobiernos de cada país que se salvaguarden los derechos humanos y la integridad de los individuos por igual si estos sienten que sus derechos están en riesgo; 0 como entes vigilantes de las personas ante ante la prevención, promoción y defensa de los derechos humanos.

Desde 1988 la comunidad internacional ha realizado múltiples pronunciamientos sobre a existencia de diversos delitos enmarcados bajo los protocolos de los derechos humanos como los del Derecho Internacional Humanitario, dicho derecho es responsable de las partes en conflicto, es decir, se debe donde no se afecte a la población civil, ya sea que estén sanos, heridos o enfermos.

El delito de desaparición forzada de personas es una violación de los derechos humanos, que de acuerdo a la CIDH debe contar con unas características especiales, para que basadas en ellas, se aborde desde lo jurisprudencial. Dentro de estas características se encuentran cional del Estado en el caso de desaparición forzada de persona.

- Recalcar la obligación del Estado. Parte del sistema interamericano de protección de derechos humanos gira en torno a tipificar este delito en su Derecho Interno conforme con estándares internacionales.

- La desaparición forzada es calificada como un delito de lesa humanidad.

De acuerdo a la Corte Interamericana de Derechos Humanos, al momento de tomar un propiciar un ambiente, en medio de la guerra

- Determinar la responsabilidad interna- caso, se encuentran con muchas dificultades para probar la culpabilidad de los autores de la desaparición forzada así como también comprobar que estas hayan sucedido; se le otorga valor probatorio a indicios, presunciones, pruebas circunstanciales e inferencias lógicas, así como también se le da un alto valor probatorio a las pruebas testimoniales y los recortes de prensa porque reproducen textualmente declaraciones públicas y además corroboran los testimonios recibidos en el proceso respecto de las desapariciones la atribución de esos hechos a las autoridades públicas.

Colombia ha sido extenso el camino que han recorrido las víctimas de desaparición forzada para que esta sea reconocida como un delito y se penalice a sus victimarios; el primer momento llegó con la Constitución Política de 1991, en la cual se establece que: "Nadie será sometido a desaparición forzada, a torturas ni a tratos o penas crueles, inhumanos o degradantes".

Así, la Desaparición Forzada de Personas es una conducta prohibida por el artículo 12 de la Constitución Política de Colombia; posterior a ella han sido creadas algunas leye en el país, con los objetivos; entre otros, de penalizar a los victimarios, salvaguardar a las víctimas y lograr que las familias tocadas por sta calamidad, hagan un cierre de la incertidumbre sentida mediante la identificación de cuerpos encontrados en fosas comunes de las cuales victimarios y demás población civil tiene conocimiento.
A pesar de que las cifras de personas desaparecidas iban en aumento día a día, y que el interés internacional por intentar frenar esta epidemia iba creciendo, solo fue hasta el año 2000 que se tipificó en nuestro Derecho Interno la conducta de desaparición forzada como tipo penal independiente del secuestro, como también una violación de Derechos Humanos y un crimen de lesa humanidad cuando reviste ciertas características. Se dio con la expedición de la Ley 589 por medio de la cual se tipifica el genocidio, la desaparición forzada, el desplazamiento forzado y la tortura y se dictan otras disposiciones.

Con posterioridad, en el año 2001 la creación de la Ley 707 se aprueba la Convención Interamericana sobre Desaparición Forzada de Personas, en donde se especifican las obligaciones que tienen los Estados dentro del sistema interamericano de protección de los derechos humanos en relación con la desaparición forzada de personas.

Dicho en otras palabras, esta Ley obliga al Estado a crear los mecanismos necesarios que garanticen su eficacia dentro del territorio nacional. La unión entre unos mecanismos efectivos, la forma en que se desarrollan y las alianzas de cooperación internacional resultan determinantes a la hora de garantizar la eficacia pretendida que no es otra que la erradicación del delito de desaparición for-

A pesar de las leyes que existían en la legislación nacional, aún no se había creado un me- 
canismo de acción rápida que permitiera ac- El proceso de Justicia y Paz surgió de las netuar inmediatamente después de ocurridos gociaciones que se habían realizado con los los hechos y de esta manera desplegar a los grupos de autodefensas, como un medio funcionarios o fuerzas armadas necesarias para lograr la paz, bajo la premisa de que no con el único objetivo de liberar a la víctima era una imposición unilateral por parte de con vida. Para estos casos, las primeras ho- gobierno, sino el resultado de un consenso ras de cometido este delito son vitales si se que implicó la concesión de algunos elebusca preservar y salvaguardar a la víctima. mentos por parte del Estado; y que tambié consagraba un procedimiento especial que Seguidamente, con la Final del formulario se aplicaba a las que han sido parte de gruLey 971 de 2005 se crea el Mecanismo de pos armados ilegales, tanto de autodefensas Búsqueda Urgente (en adelante MBU) para como de guerrilleros. Fue una Ley que se combatir la desaparición forzada; no hay que creó para obtener en cierta medida resultaesperar algún tiempo o plazo para denunciar dos instantáneos que era lo que la coyuntura e iniciar la búsqueda. Es importante mencio- politica y social exigían.

nar que es un mecanismo autónomo y por lo tanto no necesita hacer parte del proceso penal; así mismo es un servicio gratuito y puede ser solicitado por cualquier persona que conozca sobre la desaparición forzada de otra.

En ese mismo año referido, se crea la Ley 975 o más conocida como la Ley de Justicia y Paz, por la cual se dictan disposiciones para la reincorporación de miembros de grupos armados organizados al margen de la ley, que contribuyan de manera efectiva a la consecución de la paz nacional y se dictan otras disposiciones para acuerdos humanitarios.

Dicha ley es el resultado de una política gubernamental en la que se enmarca una serie de medidas dirigidas a combatir a los grupos armados ilegales y que luego del combate se buscó la negociación con sus integrantes y posteriormente la resocialización e integración a la sociedad como personas útiles.
Cinco años después se crea la Ley 1408 de 2010 la cual tiene como objetivo rendirles saparición forzada. Pero no solo eso, adicionalmente se contemplan las medidas de identificación de las víctimas entre las que $s$ incluyen: perfil genético, muestra biologica de referencia, banco de perfiles genéticos de desaparecidos y cementerios.

Con relación a los homenajes para las víctimas de desaparición forzada, se escogió e 30 de agosto como la fecha en la cual familiares, amigos y demás personas se congregan en diferentes partes del mundo para visibilizar la problemática de las víctimas, y a su vez reclamar por el desamparo en que se encuentran, como también denunciar los casos de un gran número de personas que siguen como desaparecidas y que a pesar de transcurrido el tiempo aún no se sabe nada de ellas. homenaje a las víctimas del delito de de
Después se crea la Ley 1418 de 2010, en la que se aprueba la Convención Internaciona para la Protección de todas las Personas con-

tra las Desapariciones Forzadas, adoptada en Nueva York el 20 de diciembre de 2006 en ella se establece un compromiso por alcanzar los estándares internacionales, a través de la adopción de medidas legislativas $y$ administrativas que buscan un abordaje integral frente a esta problemática, a partir de la Constitución Política que se encarga de sentar las bases normativas en la materia.

Un año después, el 10 de julio de 2011 el Presidente de la República Juan Manuel Santos sancionó la Ley 1448, más conocida como la Ley de Víctimas; en ella se dictan medidas de atención, asistencia y reparación integral a las víctimas del conflicto armado interno entre otras disposiciones. Se contempla una serie de medidas de atención, asistencia y reparación integral a las personas en condición de víctimas.

Ley que algunos consideran como la única opción posible, que abrió el espacio para que muchas personas pudieran recupera sus tierras y proteger sus vidas; mientras que para otros no es más que un intento fallido de abarcar mucho y que en la actualidad, ta y como lo señalan los indicadores, se evidencia que aún falta mucho por hacer en cuanto a la restitución de derechos de las víctimas.

Adicionalmente a las leyes nombradas, tam bién se han creado Decretos como el 051 de 2005, por medio del cual se reglamenta la aplicación de los beneficios establecidos en el Acuerdo 124 de 2004 y el procedimiento para el cumplimiento de las obligaciones tributarias a cargo de víctimas de secuestro y de desaparición forzada.

Se decretó que se harán exenciones en los siguientes impuestos distritales: Impuesto Predial Unificado (Artículo 1); Impuesto sobre Vehículos Automotores (Artículo 2); Pago de Derechos de Semaforización (Parágrafo); Impuesto de Industria y Comercio, avisos y tableros Régimen Simplificado (Artículo 3); el Impuesto Predial Unificado e Impuesto sobre Vehículos Automotores e Impuesto de Industria y Comercio, avisos y tableros Régimen Simplificado (Artículo 4).

gualmente es importante mencionar el Decreto 4218 de 2005, por medio del cual se reglamenta el artículo 9 de la Ley 589 de 2000 y tiene como objetivo diseñar, implementar, y colocar en funcionamiento con reglamentación del Registro Nacional de Desaparecidos, creado mediante la Ley 589 de 2000. Se intenta dar un paso más en el extenso recorrido que le ha tocado a familiares de las víctimas y así poder cerrar la espiral de dolor que tienen que padecer los familiares.

Por su parte, el Decreto 1862 de 2014 establece el reglamento de la Comisión de Búsqueda de Personas Desaparecidas creada por la Ley 589 de 2000. Al respecto, se han hecho muchos procesos de exhumaciones en fosas comunes en el territorio nacional para intentar calmar la frustración e incertidumbre para conocer el lugar donde están los miles de cuerpos de colombianos que aún permanecen desaparecidos. 
A pesar de que existen leyes que castigan a julio de 1998), se incorporó al ordenamiento los perpetradores y cobijan a las víctimas; jurídico colombiano, como jurisdicción comaún son muchas las agendas pendientes en plementaria; siendo declarada exequible por materia jurídica que presenta el Estado en la Corte Constitucional con la Ley 742 de cuanto al cumplimiento de dichas normas; 2002, la cual aprobó el mencionado Estatuto porque no es solo el crearlas, sino imple- de Roma, mediante la Sentencia C-578-02. mentarlas, ponerlas en práctica y así poder cumplir a cabalidad el objetivo por medio del cual fueron diseñadas.

Se puede cuestionar cómo se inició la penalización de la desaparición forzada en el año 2000 mediante el artículo 165 del Código Penal ya que esta no tiene efectos retroactivos y vale la pena recordar que el delito se empezó a presentar en el país en la década de los años 70. Quiere decir que la judicialización solo puede aplicarse a partir del 24 de julio de 2000 , fecha en que deben probarse los dos elementos fundamentales de este delito, es decir, que la persona esté privada de la libertad y que se oculte su paradero.

Por existir en nuestro país un sinnúmero de casos de desaparición forzada, se buscó desde hace algún tiempo, la modificación de las leyes para que un delito tan grave como la desaparición forzada se convirtiera en imprescriptible, y así, aunque pasara el tiempo, pudieran ser juzgados y castigados los perpetradores.

En el país, el Código Penal establecía un término de prescripción de treinta años para los delitos de desaparición forzada de personas, pero con la creación de la Ley 742 de 2002, por medio de la cual se aprobó el Estatuto de Roma de la Corte Penal Internacional (17 de Por su parte La Corte Suprema de Justicia

da determinar la imprescriptibilidad de la acción penal, siempre que no se haya identificado e individualizado a los presuntos responsables. Por ende, Colombia tiene la obligación de aplicar este tratado en toda su extensión a los actores que cometan crímenes de lesa humanidad sin excepción alguna; y más aún cuando se estableció que en este no se encontraban obstáculos a futuros procesos de paz.

Estado tiene cuatro obligaciones frente la gran mayoría de los delitos atroces: la prevención, la investigación, la sanción y la reparación. Pero es un hecho que en el caso de desaparición forzada, el Estado colombiano ha fallado en las cuatro como lo demuestran las demandas ante la Corte Interamerican de Derechos Humanos en las cuales la $\mathrm{Na}$ ción ha sido condenada (Carlos López, 2015).

En un intento de empezar a sancionarlo, el 6 de julio de 2000 se empezó a tipificar en Colombia el delito de desaparición forzada mediante la Ley 589, posteriormente ampliad en el nuevo Código Penal (Ley 599 de 2000). Esto hace que se pueda afirmar que en la legislación colombiana se han dado grandes avances en el tema. también se ha pronunciado con relación a la desaparición forzada en momentos en los cuales se llevaba el proceso de la Ley de Justicia y Paz; en esa coyuntura específica se realizaron las primeras condenas para responsables militares de las organizaciones paramilitares, así como la de altos funcionarios del Estado señalados de complicidad o pertenencia a dichos grupos.
El terreno de La Escombrera se convirtió en el lugar donde se desaparecía, se mataba y se cubría con tierra el producto de esta violenta lucha por controlar el territorio. Tal y como lo narra uno de los testigos sobrevivientes:

Los paramilitares patrullaban, desde aquí, desde las lomas, hasta la estación del metro de San Javier. En esos recorridos cogían a la gente y la subían para acá en camionetas. No solo eran jóvenes, también había niños, mujeres en embarazo y gente ya mayor. A veces no los mataban de una, los tenían metidos en esas piezas durante días, a las mujeres las aprovechaban sexualmente y a algunos los dejaban desnudos para que no se volaran. Eligieron dos habitaciones como sitios de tortura: una estaba en una casa y otra en una pequeña empresa de fundición de metales. Se escuchaban los quejidos tan espantosos. Cuando pudimos, nos asomábamos y veíamos que con los aerosoles con los que ellos pintaban los muros les prendían candela en los ojos, que tenían que hablar, que tenían que decir quiénes eran guerrilleros. También era frecuente que los paramilitares pasaran por las casas pidiendo palas y cuchillos prestados. Eran tan salvajes que nos devolvían todo eso con la sangre y la carne fresca, continúa el hombre, y afirma que después de la tortura subían a la gente, solos o en pequeños grupos, amarrados con lazos o cabuyas, y regresaban sin ellos, u obligaban a los conductores de volquetas a cargar los muertos $\mathrm{y}$ a sepultarlos entre escombros. (Escobar Roldán, 2016) 
La lucha jurídica por desenterrar La Escom- del Derecho. En este trabajo se han enunbrera finalizó el mes de septiembre de 2013, cuando el Tribunal Superior de Medellín ordenó que se exhumaran los cadáveres, enfrentando y prevaleciendo los derechos de las víctimas contra los derechos del capital privado, de empresas poderosas que usufructan la extensión de tierra. En la actualidad la Fiscalía General de la República sigue trabajando en el sitio con el fin de exhumar los cadáveres y poder rastrear la identidad de los desaparecidos.

El fallo judicial de La Escombrera es un éxito en la larga lucha de las víctimas por hacer valer la normatividad conquistada. De ahí que el postconflicto y el escenario que ofrece, implique revisar las agendas pendientes de un problema que aún sigue vigente $y$, como se ha planteado en párrafos anteriores, perviva el "duelo congelado" de las víctimas.

Uno de los temas candentes es retomar la idea de la Comisión de la Verdad. Esta idea no se ha asumido en el acontecer nacional, a pesar de la amplia experiencia de las Comisiones de la verdad en otros escenarios. Determinar culpables y encontrar procesos de opinion pública que puedan hacer eco de este proceso y del rol de los actores armados en el accionar delictuoso seria fundamental para un proceso de verdad jurídica. Esta es una tarea pendiente, que se ha logrado direccionar de otra forma por los estudios de Centro Nacional de Memoria Histórica, pero es necesario un debate nacional que visibilice la terrible dimensión de los hechos.

Es necesario apalancar el poder simbólico ciado las conquistas jurídicas de las víctimas, pero es necesario propiciar movilizaciones en torno a los fallos judiciales y a la jurisprudencia que se ha logrado construir en torno a la temática. Pero como lo mencionábamos inicio del trabajo, nos encontramos con un campo jurídico en construcción, concepto tomado del sociólogo frances Pierre Bourdieu (2002), para explicar un escenario de luchas hegemónicas por el poder. El Derecho no escapa a esta tendencia; por el contrario fuerzas que logran materializar la propuest jurídica y restaurar la desarmonía y las fuerzas que se niegan y quieren preservar sus fuerzas alter-legales, es decir, los micropoderes heterárquicos y hegemónicos (Foucault, 1991). Esta lucha que se dirime en el litigio, es una lucha entre las movilizaciones sociales que genera el Derecho, la fuerza institucional y los poderes fácticos. Lo interesante de la propuesta de Latorre (2015), es que en la medida en que se empoderen comunidades, se socialicen las gramáticas jurídicas y se logre el espacio deliberativo, el Derecho

El otro escenario, y este es el peligroso, es que el poder simbólico no sea operativo, es decir, se continúe en el síndrome normativo (Botero Bernal, 2003), que a cada problema social se le decrete una normatividad sin tener la fuerza institucional de hacer operativo ese orden normativo. En este sentido Derecho pierde su fuerza, se torna opaco y los colectivos sociales pierden la fe en e orden jurídico y en las instituciones que lo refrendan. se instituye en campo de combate entre las puede transformar las realidades.
Por ello la necesidad de hacer memoria, de instaurar una memoria jurídica que permita entender la violencia padecida, que recobre y visibilice las voces de las víctimas y que ante todo sea capaz de recuperar los rastros y huellas de los desaparecidos, para que Colombia no tenga más Escombreras que horadar y para que no se repitan nunca más las atrocidades y vejamenes a los inocentes.

En este sentido es pertinente cerrar este trabajo con las afirmaciones de las víctimas de Nariño en la Conmemoración del Día Internacional de la Desaparición Forzada: “Ustedes cierran los ojos y olvidan, nosotros ceramos los ojos y recordamos"

\section{REFERENCIAS}

Acemoglu, D. y Robinson, J. (2012). Por que fracasan los países: los orígenes del poder, la prosperidad y la pobreza. Barcelona: Ediciones Deusto.

Aguilar Cavallo, G. (2009). La desaparición forzada de personas: naturaleza, fuentes $y$ jerarquía. Comentario a la sentencia del Tribunal Constitucional relativo a la Convención Interamericana sobre desaparición forzad de personas. Estudios Constitucionales, 7(2) 429-463. Centro de Estudios Constitucionaes de Chile. Santiago, Chile.

Alflen Da Silva, P. R. (2010). El delito de desaparición forzada de personas y el Derecho Penal brasileño. Revista de Derecho (Valparaíso), (XXXIV), 213-226. Pontificia Universidad Católica de Valparaíso. Valparaíso, Chile.
Amnistía Internacional (2014). Informe Amnistía Internacional. La situación de los derechos humanos en el mundo. Amnesty International Peter Benenson House 1 Easton Street, Londres $1 \mathrm{X}$.

Apter, D. (1997). The legitimization of violence. NYU Press.

Botero Bernal, A. (2003). Diagnóstico de la eficacia del Derecho en Colombia y otros ensayos. Medellín: Biogénesis, Señal.

Bourdieu, P. (2002). Poder, Derecho y clases sociales. Desclée de Brouwer.

Carcova, C. M. (2009). Acceso a la justicia: exclusión y aculturación. En http://www.urbeetius.org/newsletters/02/Carcova.pdf

Centro Nacional de Memoria Histórica (2014). Textos corporales de la crueldad. Memoria histórica y antropología forense. Bogotá: $\mathrm{CNMH}$.

Centro Nacional de Memoria Histórica (2014). Desaparición forzada Tomo I: Normas y dimensiones de la desaparición forzada en Colombia. Bogotá: Imprenta Nacional.

Centro Nacional de Memoria Histórica (2013). Desaparición forzada Tomo II: Huelas y rostros de la desaparición forzada (1970-2010). Bogotá: Imprenta Nacional.

Centro Nacional de Memoria Histórica (2014). Desaparición forzada Tomo III: Entre la incertidumbre y el dolor: impactos psicosociales de la desaparición forzada. Bogotá: Imprenta Nacional. 
Centro Nacional de Memoria Histórica Congreso de la República de Colombia. Co(2014). Desaparición forzada Tomo IV: Balan- lombia.

ce de la acción del Estado colombiano frente

a la desaparición forzada de personas. Bogotá: Imprenta Nacional.

Centro Nacional de Memoria Histórica (2015). El derecho a la justicia como garantía de no repetición. Volumen 1. Graves violaciones de derechos humanos, luchas sociales y cambios normativos e institucionales 1985 2012. Bogotá: CNMH.

Centro Nacional de Memoria Histórica (2016). El derecho a la justicia como garantía de no repetición. Volumen 2. Las víctimas y las antesalas de la justicia. Conclusiones y Recomendaciones. Bogotá: $\mathrm{CNMH}$.

Centro Nacional de Memoria Histórica Decreto 1862 de 2014. Por el cual se estable(2016). Hasta encontrarlos. El drama de la ce el reglamento de la Comisión de Búsquedesaparición forzada en Colombia. Bogotá: da de Personas Desaparecidas creada por CNMH.

Comisión Internacional de Juristas (2005) Colombia: políticas del Gobierno socavan el Estado de Derecho y consolidan la impunidad. Ginebra SUIZA. Disponible en: http:// www.acnur.org/t3/uploads/media/COI 971. pdf

Consejo Noruego de Refugiados (2016). Ca sos dramáticos de desplazamiento. Recuperado de: http://www.prensalibre.com/ internacional/violencia-y-guerras-obligan-a38-millones-de-personas-a-desplazarse-enel-mundo

Constitución Política de Colombia (1991)
Ley 589 de 2000. Presidente de la República de Colombia.

Corte Suprema de Justicia (2008). Sala de Casación Penal, auto de segunda instancia. Radicación 29472.

Corte Suprema de Justicia (2009). Sala de Casación Penal. Aprobado Acta № 374.

Decreto 051 de 2005. Por medio del cual se establecidos en el Acuerdo 124 de 2004 y e procedimiento para el cumplimiento de las gaciones tributarias a cargo de víctimas e secuestro y de desaparición forzada. Registro Distrital 3283. El Alcalde Mayor de BoDecreto 4218 de 2005. Por el cual se reglamenta el artículo $9^{\circ}$ de la Ley 589 de 2000. Diario Oficial 46101. Presidente de La República de Colombia, noviembre 23 de 2005.

Escobar Roldán, M. (2016). Los testigos vivos de La Escombrera. Periódico El Tiempo. Recuperado: http://www.eltiempo.com/ colombia/medellin/los-testigos-vivos-de-laescombrera-en-medellin/16400541

Foucault, M. (1991). Vigilar y castigar: El nacimiento de la prisión. Buenos Aires: Siglo XXI. reglamenta la aplicación de los beneficios
Friedman, T. (2006). La tierra es plana: breve historia del mundo globalizado del siglo XXI. Barcelona: Martínez Roca.

Colombia. En <http://www.law.yale.edu/ documents/pdf/sela/J julietaLemaitre_Spanish_.pdf> acceso abril de 2010

García Villegas, M. (2003). Derecho y sociedad en América Latina: un debate sobre los estudios jurídicos críticos. Bogotá: ILSA.

Gatti, G. (2011). El lenguaje de las víctimas: silencios (ruidosos) y parodias (serias) para hablar (sin hacerlo) de la desaparición forzada de personas. Universitas Humanistica (72), julio-diciembre, 89-109. Pontificia Universidad Javeriana. Bogotá, Colombia.

Ley 1408 de 2010. Por la cual se rinde homenaje a las víctimas del delito de desaparición forzada y se dictan medidas para su localización e identificación. Diario Oficial No. 47.807. Congreso de la República. Agosto de 2010 .

Ley 1418 de 2010. Por medio de la cual se aprueba la "Convención Internacional para la Protección de todas las personas contra las desapariciones forzadas", adoptada en NueGiraldo Marín, L. A., Gómez Gómez, J. D. y va York el 20 de diciembre de 2006. Diario Maestre Caro, K. (2008). Niveles de depre- Oficial No. 47.910. Congreso de la República. sión y estrategias de afrontamiento en fami- Diciembre de 2010

liares de víctimas de desaparición forzada en la ciudad de Medellín. International Journal of Psychological Research, 1(1), 27-33. Universidad de San Buenaventura. Medellín, Colombia.

Goldhagen, D. (2010). Peor que la guerra: geocidio, eliminacionismo y la continua agre sión contra la humanidad. Barcelona: Taurus.

Latorre Iglesias, E. L. (2015). Litigio estructural y experimentalismo jurídico: análisis sociojurídico a los cambios generados por la Sentencia T-025 en la población desplazada. Santa Marta: Fondo de Publicaciones Universidad Sergio Arboleda. recho, violencia y movimientos sociales en Julio de 2005 
Lira Kornfeld, E. (2006). Los actos de la dictadura. Comisión investigadora 1931. Chile: Universidad Alberto Hurtado.

NTX (2016). Historia del conflicto armado en Colombia. Recuperado en: http://www.hoytamaulipas.net/infografias/253/Colombiahistoria-del-conflicto-armado-.html

Organización de las Naciones Unidas (2012). Informe de misión a México: grupo de trabajo de la ONU sobre las desapariciones forzadas o involuntarias. México: ONU.

Pecaut, D. (2001). Guerra contra la sociedad. Barcelona: Espasa.

Ramírez Páez, D. y Segura, J. A. (2013). Comportamiento del fenómeno de la desaparición en Colombia. Bogotá: Instituto Nacional de Medicina Legal y Ciencias Forenses.

Reveles, J. (2015). México: país de desapariciones forzadas. Política y cultura, (43), 9-23. Universidad Autónoma Metropolitana Unidad Xochimilco. Distrito Federal, México.

Sentencia C-317 (2002, mayo 2). Demanda de inconstitucionalidad contra el artículo 165 (parcial) de la Ley 599 de 2000 "por la cual se expide el Código Penal". M.P. Clara Inés Vargas Hernández. Corte Constitucional. Bogotá D.C.
Sentencia C-370 (2006, 18 mayo). Sentencia de Constitucionalidad. M.P. Manuel José Cepeda Espinosa, Jaime Córdoba Triviño, Rodrigo Escobar Gil, Marco Gerardo Monroy Cabra, Álvaro Tafur Galvis, Clara Inés Vargas Hernández. Corte Constitucional.

Sentencia C-580 (2002, julio 31). Revisión oficiosa de la "Ley 707 del 28 de noviembre de 2001 'Por medio de la cual se aprueba la Convención Interamericana sobre Desaparición Forzada de Personas'" hecha en Belem do Pará, el nueve de julio de 1994. M.P. Rodrigo Escobar Gil. Corte Constitucional. Bogotá D.C.

Sentencia C-781 (2012, 10 octubre). Demanda de inconstitucionalidad contra el artículo 30 (parcial) de la Ley 1448 de 2011, "por la cual se dictan medidas de atención, asistencia y reparación integral a las víctimas del conflicto armado interno y se dictan otras disposiciones. M.P. María Victoria Calle Correa. Corte Constitucional.

Statista (2016). Víctimas del conflicto en Colombia. Recuperado en: https://es.statista. com/grafico/5607/las-victimas-de-los-conflictos-armados-en-colombia/

Vosganian, V. (2010). El libro de los susurros. Valencia: Pre-Textos. 